\title{
Conformational space and vibrational spectra of 2-[(2,4-dimethoxyphenyl)amino]-1,3-thiazolidin-4-one
}

\author{
Alicja Nowaczyk • Marcin Kowiel • Andrzej Gzella • \\ Lukasz Fijałkowski • Volodymyr Horishny • \\ Roman Lesyk
}

Received: 14 March 2014 / Accepted: 22 June 2014 / Published online: 15 July 2014

(C) The Author(s) 2014. This article is published with open access at Springerlink.com

\begin{abstract}
In this work we present the results of a study of the $\mathrm{X}$-ray structure of 2-[(2,4-dimethoxyphenyl)amino]-1,3thiazolidin-4-one. Using the FTIR spectra in solid state and results of ab initio calculations we explain the issue of the tautomerism of this molecule. The compound is shown to exist as the 2-amino tautomer rather 2-imino tautomer. Here we consider eight possible tautomers. On the basis of the vibrational spectra we can eliminate five possible tautomers, as not existing in the solid state. As the most possible tautomeric form we have found keto 2-amino form.
\end{abstract}

Keywords ab initio calculations $\cdot$ FTIR spectral characteristics $\cdot$ Tautomerism $\cdot$ 1,3-thiazolidin-4-one $\cdot \mathrm{X}$-ray analysis

\section{Introduction}

The 1,3-thiazolidin-4-one as saturated form of thiazole ring is heterocyclic nucleus that has sulfur and nitrogen atoms at

Electronic supplementary material The online version of this article (doi:10.1007/s00894-014-2366-6) contains supplementary material, which is available to authorized users.

\footnotetext{
A. Nowaczyk $(\square) \cdot$ Ł. Fijałkowski

Department of Organic Chemistry, Faculty of Pharmacy, Collegium Medicum in Bydgoszcz, Nicolaus Copernicus University, Dr. A. Jurasza 2, 85-094 Bydgoszcz, Poland

e-mail: alicja@cm.umk.pl

M. Kowiel • A. Gzella

Department of Organic Chemistry, Poznan University of Medical

Sciences, ul. Grunwaldzka 6, 60-780 Poznań, Poland

V. Horishny $\cdot$ R. Lesyk

Department of Pharmaceutical, Organic and Bioorganic Chemistry, Faculty of Pharmacy, Danylo Halytsky Lviv National Medical University, Pekarska 69, 79010 Lviv-10, Ukraine
}

position 1 and 3, and a carbonyl group at position 4 respectively. It represents an important structural moiety included in many compounds of pharmacological importance and have been subjected to extensive study in recent years [1]. The thiazolidinone ring has been incorporated into a broad range of known biologically active compounds, either as a substituent group or a replacement of another ring. These have motivated researchers to synthesize compounds containing the mentioned heterocyclic moiety. The thiazolidin-4-one scaffold is very flexible despite the presence of sulfur, nitrogen, and oxygen atoms. Combination of such molecular flexibility and fundamental heteroatoms yield almost all types of biological activities. Consequently the thiazolidin-4-one fragment can be found in a number of clinically used drugs. Biological screening has demonstrated activities such as bactericidal, pesticidal, fungicidal, insecticidal, antiviral (antiHIV), antidiabetic, anticonvulsant, tuberculostatic, antiinflammatory, antithyroidal, anticancer, antithyroidal, and immunostimulant [2-6]. According to this the thiazolidin-4one fragment is considered to be a wonder nucleus. Some thiazolidin-4-ones have potentiation of pentobarbital-induced sleeping time, antihypertensive $[3,5,4]$. It is worth mentioning that substituents in the 2-, 3-, and 5-positions may be varied, but the greatest difference in structure and properties is exerted by the group attached to the C2-position [7-10]. Thus a few derivatives with $\mathrm{C} 2$ and $\mathrm{N} 3$ substituted positions and the presences of electron-withdrawing substitution on aromatic ring on $\mathrm{C} 2$ position of thiazolin-4-one presenting varied degrees of inhibition against Gram-positive and Gram-negative bacteria showing inhibition as good as the standard drugs used. On the other hand, retrospective analysis of these compounds showed that anticancer activity increases while replacement from cycloalkyl moiety to heteryl moiety in position $\mathrm{C} 2$ [2].

A detailed study of the characteristic bands in the infrared spectra of several 2-substituted thiazolidin-4-ones has been 
done in the past $[11-14,10]$. The imino-amino tautomerism of 2-substituted thiazolidin-4-ones was studied by infrared spectroscopy $[15,16]$. Taylor et al. [17] described the criteria for determining the cis and trans configurations of these compounds. The cis isomer is favored when $\mathrm{H}$-bonding exist in the system otherwise the isomer is impossible. In other conditions, the trans isomer is the stable form. It was shown by the methods of IR (and NMR) spectroscopy that 2aminothiazolin-4-one ("pseudothiohydantoin") exists in an imine form in the crystalline state and in solutions in dimethyl sulfoxide, water, and trifluoroacetic acid, and in this form the N3-C2 bonds are partially double [4]. Theoretical ab initio studies could supplement these measurements. Additionally, calculations of energy, atomic charges, minimum energy structures, geometry, and natural bond orbital (NBO) could indicate the electronic density distribution of each atom. Nowadays, the formulation of predictive theoretical models is necessary in pharmaceutical research because of the considerable reduction of cost and avoidance of animal testing. The constitution of the 2-iminothiazolidin-4-one, also known as pseudothiohydantoin [18], was first proposed by Liebermann et al. in $1879[19,20]$. However, the discussion on the tautomerism of this molecule continued for more than a century [14]. Their tautomerism was studied experimentally by different authors. From the information available in the literature the 2-iminothiazolin-4-one and its 2-aryl derivatives are shown to exist as the 2-amino tautomer rather than 2-imino tautomer [2, $21,22]$. The title compound can exist as eight possible tautomers, Fig. 1 a-h. In the solid state its infrared spectrum shows the presence of a carbonyl absorption and the absence of an hydroxyl absorption, thereby eliminating five possible tautomers (a, b, e-g). In this work we present theoretical and experimental investigation on the X-ray crystallography and IR spectra of the above mentioned structures with ab initio methods.

\section{Materials and Methods}

\section{Synthesis procedure}

The compound described in this paper was synthesized by the reaction protocols typically used for obtaining 2-arylamino1,3-thiazolidin-4-one derivatives [23]. The starting 2carbethoxymethylthio-2-thiazolidin-4-one was obtained by the reaction of 2-thioxothiazolidin-4-one triethylammonium salt with ethyl chloroacetate in acetone. Reaction of 2 carbethoxymethylthio-2-thiazolidin-4-one with a 2,4dimethoxyaniline in refluxing ethanol provided target 2-[(2,4-dimethoxyphenyl)amino]-1,3-thiazolidin-4-one with $80 \%$ yield. The product formed was filtered, washed, dried, and crystallized from n-butanol.

\section{Structural analysis}

The structure of the studied compound was confirmed using the X-ray crystallography and IR spectroscopy. The X-ray diffraction measurements were carried out using Agilent Xcalibur A diffractometer, detailed crystallographic information is included in Supporting information. The mid infrared
Fig. 1 The 2-[(2,4-

dimethoxyphenyl)amino]-1,3thiazolidin-4-one for the imino $\leftrightharpoons$ amino and keto $\leftrightharpoons$ enol tautomeric forms

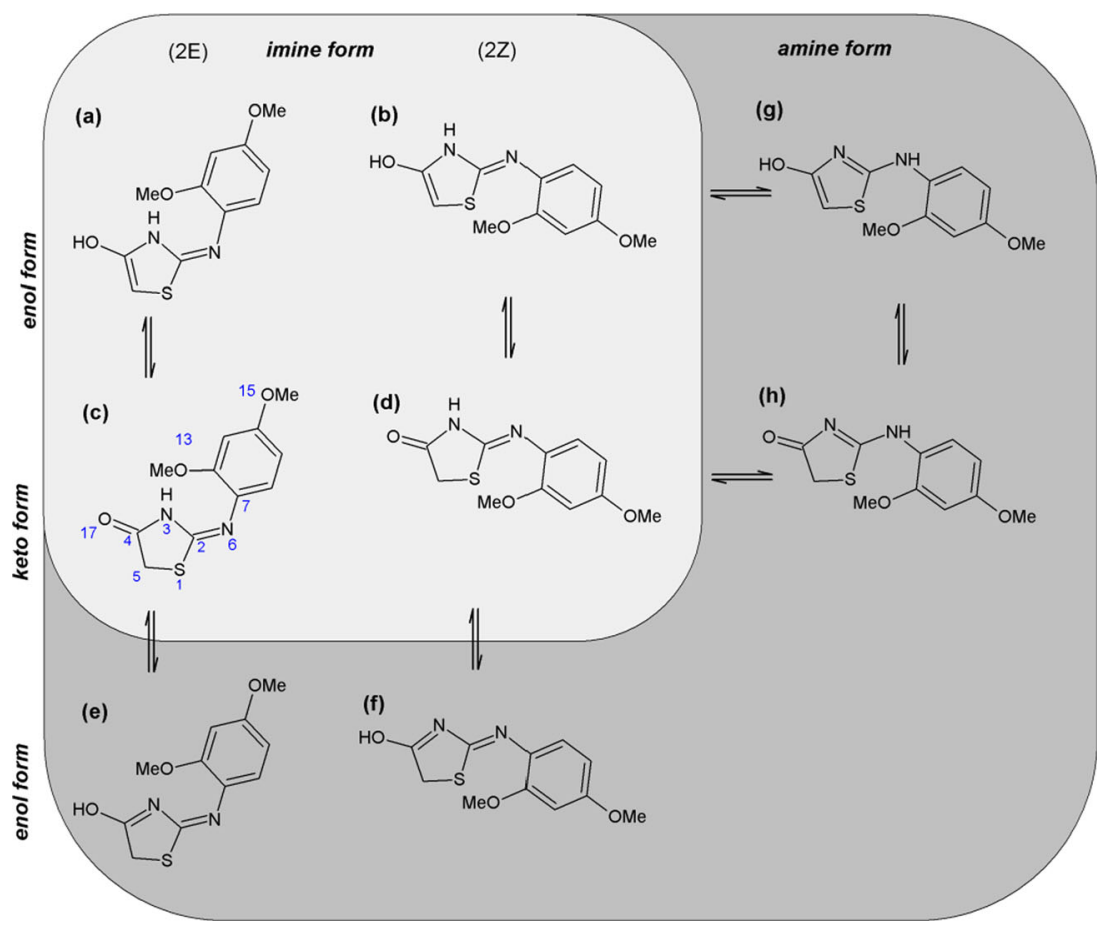


region the FT-IR spectrum of 2-[(2,4dimethoxyphenyl)amino]-1,3-thiazolidin-4-one was recorded in $\mathrm{KBr}$ pellet. The spectrum was taken with a Bruker IFS 66v/ S FT-IR spectrophotometer equipped with a DTGS detector; resolution $2 \mathrm{~cm}^{-1}$. The Happ-Genzel apodization function was used [24].

\section{Computations}

The title compound can exist in several possible tautomers shown in Fig. 1 a-h. In this work the 3dimensional structures of the 1,3-thiazolidin-4-one tautomers in their neutral state were obtained by the DFT [25] approach utilizing Becke's three parameter functional [26] with the Vosko et al. [27] local and Lee et al. [28] non-local correlation, abbreviated as B3LYP. The ab-initio quantum chemical calculations using standard Pople's 6-31G(d,p) basis set [29] including d polarization functions for carbon, nitrogen, and oxygen and $\mathrm{p}$ polarization functions for hydrogen atoms. The rotations about the C2-N6 (Fig. 1 g-h.), N6-C7 (Fig. 1 a-f.) bonds respectively were taken into account. We have calculated the rotational energy barrier by steps of $10^{\circ}$ around. We take the X-ray structure of the 2-[(2,4-dimethoxyphenyl)amino]-1,3-thiazolidin-4-one (Fig. 1h.), as starting geometries for all studied compounds. All eight tautomers presented in Fig. 1 were considered in our study. All the molecules were geometry-optimized until the root-mean-square (RMS) gradient value was smaller than $10^{-6}$ a.u. To structurally characterize the molecule in detail, a systematic investigation of its potential energy surface was undertaken at the DFT(B3LYP)/6-31++G(d,p) level of approximation [30]. Later, using the surface data generated from Gaussian checkpoint files, and GaussView 4.1 software, the distribution of charge in a molecule was calculated. To obtain a 3D plot of the MEP, the electrostatic potential cube file was calculated from total SCF density. The contour maps of the electrostatic potential were then drawn using a distance between grid points of $0.02 \AA$ and the isovalues 0.0004 . The Gaussian software suite was used to calculate the electrostatic potential maps and surfaces as the distribution of the potential energy of a unit positive charge in a given molecular space, with a resolution controlled by the grid density.

The vibrational wavenumbers were calculated at the DFT(B3LYP)/6-31++G(d,p) level of approximation. It is well known in the quantum chemical literature that among the available functionals, the B3LYP functional yields a good description of harmonic vibrational wavenumbers for smalland medium-sized molecules.

All calculations were performed using the Gaussian 03 program [32]. The visualizations were prepared by use of the Gaus-View 4.1 [33]. Theoretical calculations were conducted on the Cluster Supercomputer at Nicolaus Copernicus University Computational Center.

\section{Results and discussion}

\section{Tautomeric forms}

The tautomeric forms of the studied compound together with numbering system are shown in Fig. 1. The 2-substituted 1,3thiazolidin-4-one can exist as 2-amines, in which the electron pair of the $\mathrm{sp}^{2}$-hybridized nitrogen atom is in conjugation with the four $\pi$ electrons of the $\mathrm{C}=\mathrm{C}$ and $\mathrm{C}=\mathrm{N}$ double bond (Fig. 1g). There also exist the 2-amine tautomer in which the electron pair of the $\mathrm{sp}^{2}$-hybridized $\mathrm{N}$ atom is conjugated with four $\pi$ electrons of the $\mathrm{C}=\mathrm{O}$ and $\mathrm{C}=\mathrm{N}$ double bonds respectively (Fig. 1h). Additionally there are two tautomers of 2imine in which there is conjugation including $\pi$ electrons of the two $\mathrm{C}=\mathrm{N}$ double bond (Fig. $1 \mathrm{e}-\mathrm{f}$ ). There are as well four tautomers having no conjugated double bonds whatsoever (Fig. $1 \mathrm{a}-\mathrm{d}$ ). On account of the mobility of the hydrogen atom of the $\mathrm{CH}_{2}$ group in position 5 the pair of a-c, b-d, g-h can be in tautomeric equilibrium. Simultaneously on account of the mobility of the hydrogen atom of the NH group a (or b) -g, and $\mathrm{c}$ (or d) -h and c-e, d-f can be in tautomeric equilibrium. Theoretically, $\mathrm{E} / \mathrm{Z}$ isomerism is possible across the double bond a-b, c-d, e-f and the molecule may exist in the 2-imino form with the possibility of interconvertion via 2-amino tautomer (e-h) as depicted in Fig. 1. According to Taylor and coworkers and Steel et al. [31, 11, 12, 17] the $Z$-isomer predominates when H-bonding occurs, otherwise this isomer is impossible. In other conditions, the $E$ isomer is the stable form.

\section{2-amino(imino)-1,3-thiazolidin-4-ones -CSD studies}

In our laboratory, the crystal structures of various thiazolidin4-ones have been investigated in the past few years $[10,23,7$, $32,8,33,34]$. A lot of 2-amino(imino)-1,3-thiazolidin-4-ones have been found in the Crystal Structure Database (CSD version 5.35, Jun 2014) [35]. The CSD searches for 2-amino(imino)-1,3-thiazolidin-4-one derivatives with or without $\mathrm{C}-5$ and $\mathrm{N}-3$ substituted positions were done for the neutral forms of the species. The list of all found structures and geometrical specifications can be found in Tables S1-S7 in Supporting information. The search has resulted in 97 hits, of which 30 hits having molecules containing N3 or N6 secondary amine group (Table S1-S2). In the case of 21 possessing substituent at the $\mathrm{C}-2$ and $\mathrm{C}-5$ positions of the thiazolidin-4-one moiety (16 bearing 2-amino Table S1 and five 2-imino forms Table S2 respectively). In the case of the remaining 67 hits, the 
structures contain tertiary amine group (Table S3-S4) of which 49 hits having substituent at the 3-position at the heterocyclic ring (Table S3) and 18 having substituent at the N6 position (Table S4). Thus the search showed that the population of the structure containing tertiary amine group and substituents at the $\mathrm{C}-2$ and $\mathrm{C}-5$ position of the thiazolidin-4-one results in 37 hits. It can be remarked that 22 hits possessed substituents at the C-2 and C-5 position and amine N3 atom and 15 hits which has a substituent at the $\mathrm{C}-2$ and $\mathrm{C}-5$ position and amine N6 atom. In the literature attention was mainly drawn to the imine $\leftrightharpoons$ amine conversion. However, the majority of tautomeric equilibrium of heteroatomic molecule are prototropic, i.e., involve proton migration between (i) carbon and $\mathrm{O}$ center; (ii) nitrogen and $\mathrm{O}, \mathrm{N}$ centers. From a chemical point of view, another tautomerism such as keto $\leftrightharpoons$ enol is also possible (Fig. 1.). Among 2-amino (imino)-1,3-thiazolidin-4-ones deposited in the CSD database, though, none adopts the enol tautomeric form. Based on 20 derived 2-amine structures deposited in the CSD database the average bond length values for C2-N3 estimated as 1.325(1) ̊́ and C2-N6 as 1.315(2) $\AA$ (Supporting information, Table S5) were calculated. Comparing these values with normal length of double bond for $\mathrm{C}=\mathrm{N}$ $(1.279(1) \AA)$ and single bond Csp2-N (1.383(1) $\AA)$ [36, 37] (Supporting information, Table S6) indicates that the first is extended in comparison to the length of the double bonds by $0.046 \AA$, and the next is shorter by $0.068 \AA$ with respect to the single bond length. These results show that these two bonds have a partial double-bond character in the molecules. Moreover the average length of $\mathrm{C} 2-\mathrm{N} 3$ and $\mathrm{C} 2-\mathrm{N} 6$ bonds were also calculated for eight derivatives of 2-imine. The length of $\mathrm{C} 2-\mathrm{N} 3$ bonds was estimated as 1.374(3) $\AA$ and $\mathrm{C} 2-\mathrm{N} 6$ bond as 1.280(2) $\AA$ (Supporting information, Table S5). The former is similar to the typical single $\mathrm{Cs} p^{2}-\mathrm{N}$ bond length. The latter is close to $\mathrm{C}=\mathrm{N}$ bond length. The mutual position of thiazolidin-4-one in $E / Z$ point of view may be described by the value of S1-C2-N6-C7 torsional angle (Supporting information, Table S7). The separate analyses revealed that, in the majority of hits, the torsion angle values are around $0^{\circ}$ and exhibit more or less coplanar conformation. Such a predominant conformation found in CSD database is $2 Z$.

\section{Crystallographic and calculated structures}

X-ray analysis revealed that compound 1 occurs in crystal in 2-amine form (Fig. 1h, 2 and Table 1). This was confirmed by the presence of hydrogen atom connected to the exocyclic nitrogen $\mathrm{N} 6$ and similar values of $\mathrm{C} 2-\mathrm{N} 3$ and $\mathrm{C} 2-\mathrm{N} 6$ bond lengths [1.3265(11) and 1.3247(11) $\AA$, respectively], which is a typical observation for this tautomeric form. It can be remarked that both bonds mentioned above reveal partially double character. They are shortened by about 38 and $39 \sigma$ with respect to the normal single $\mathrm{Cs} p^{2}-\mathrm{N}$ length 1.383(2) $\AA$ $[37,36]$. On the other hand, they are lengthened by about 32

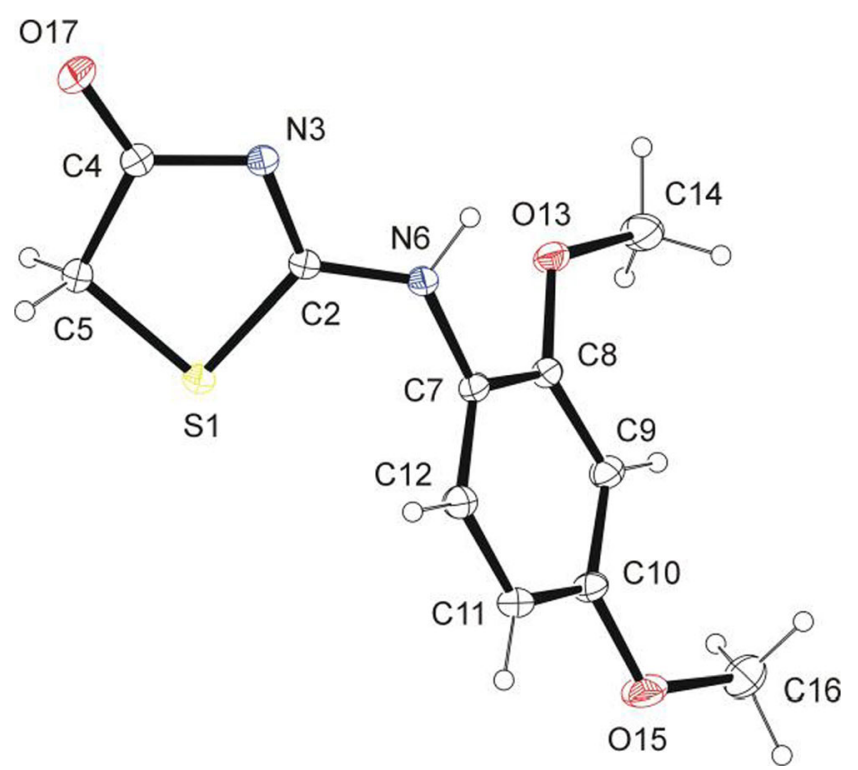

Fig. 2 X-ray crystal structure (ORTEP plot) of 1. The crystallographic data in the CIF form are available as electronic supplementary information from the Cambridge Crystallographic Database Centre (CCDC 1003815)

and $31 \sigma$ in comparison with the literature double $\mathrm{C}=\mathrm{N}$ bond length 1.279(1) $\AA[37,36]$. The bond $\mathrm{C} 2-\mathrm{N} 6$ displaying partially double character hinders the rotation of $\mathrm{N} 6-\mathrm{C} 7$ bond. As a result, C7 only slightly sticks out of the least-squares plane of thiazolidin-4-one. The observed torsional angle $\mathrm{S} 1$ $-\mathrm{C} 2-\mathrm{N} 6-\mathrm{C} 7,2.43(12)^{\circ}$ indicates that $\mathrm{S} 1-\mathrm{C} 2$ and $\mathrm{N} 6-\mathrm{C} 7$ bonds are in synperiplanar orientation. The observed conformation create favorable conditions to form $\mathrm{N} 6-\mathrm{H} 6 \cdots \mathrm{N} 3^{\mathrm{i}}$ [(i) $1-\mathrm{x}, 1-\mathrm{y},-\mathrm{z}]$ hydrogen bonds in crystal which connect the molecules related by the inversion center into dimers (Fig. 3). In the latter thiazolidinone moieties are arranged coplanar. This is different from the phenyl and thiazolidinone systems, which form a dihedral angle $59.05(4)^{\circ}$. The reason for such a large dihedral angle should be seen in the presence of the methoxy group in the ortho position of the phenyl ring, preventing flattening of the molecule.

The optimized structure produced is very similar to the experimental one. Both the optimized and experimental structures of the title molecules were compared by superimposing them using a least-squares algorithm that minimizes the distances between the corresponding non-hydrogen atoms as shown in Fig. 4. The color code of these compounds are: yellow for the crystallographic structure, and the other colors represent calculated structures such as: platinum a, red b, violet $\mathrm{c}$, purple $\mathrm{d}$, gray e, blue $\mathrm{f}$, green $\mathrm{g}$, lemon $\mathrm{h}$.

Potential energy studies

Rotation around the $\mathrm{C} 2-\mathrm{N} 6$ and $\mathrm{C} 7-\mathrm{N} 6$ bonds is possible exclusively in amine and imine respectively. The analysis of the adequate potential energy surfaces by means of redundant 
Fig. 3 The centrosymmetric hydrogen-bonded dimer of $1 \mathrm{~h}$ [symmetry code: (i) $0.5-\mathrm{x}, 0.5-\mathrm{y}$,z]

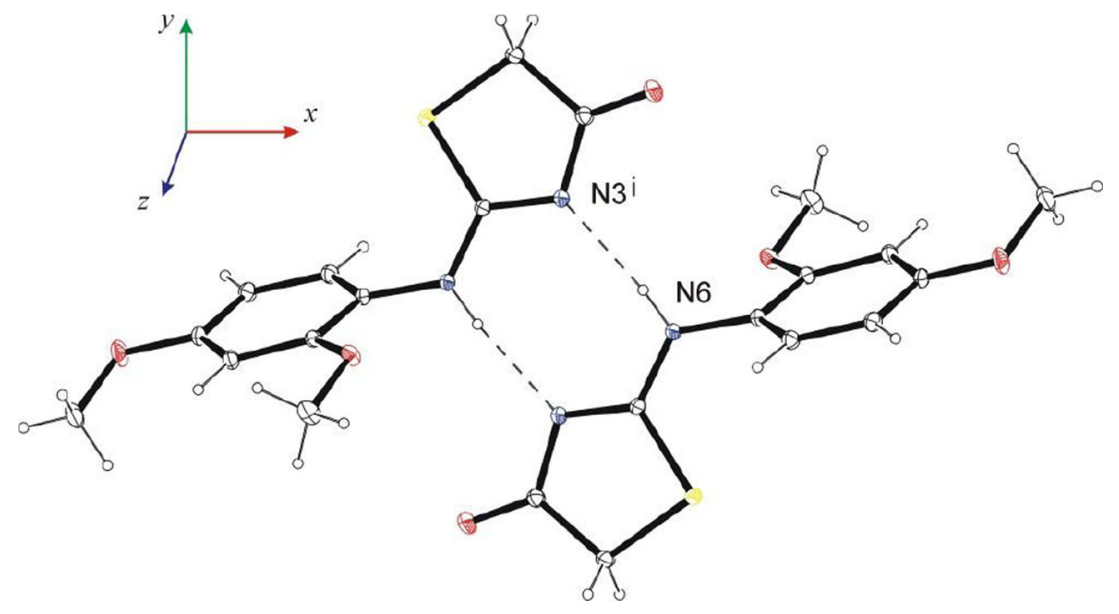

coordinate technique indicate the existence of eight absolute minima, which correspond to the most stable conformers of investigated structures. The matrix of energy differences between every pair of structures investigated in this paper is given in Table 2. Taking into account the calculated relative energy barriers for the different conformers the most stable in the gas phase are conformer $h$ and $d$, due to the highest energy differences of other compounds (Table 2). However the minimum differences of energy was observed in d-h pair, i.e., about $2 \mathrm{kcal} \mathrm{mol}^{-1}$ which suggests that $2 \mathrm{Z}$ imine and amine counterpart may not be experimentally accessible as isolate species. Nowadays the most information on conformational isomerism comes from single-crystal X-ray diffraction studies. According to the experimental observations the separation of the conformers as chemical isolate form can be accessible if $\Delta \mathrm{E} \approx 20-30 \mathrm{kcal} \mathrm{mol}^{-1}$. As it can be see in Table 2 the keto

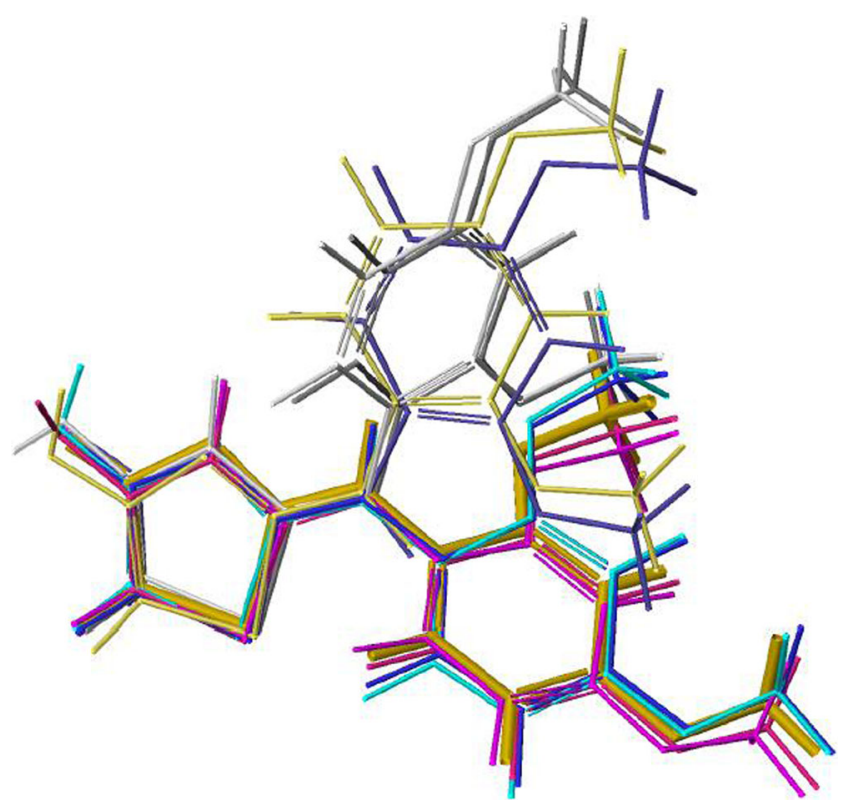

Fig. 4 Frontal view of the most stable calculated structures obtained by superimposing with the X-ray structure overlapped by calculated structures tautomers are generally lower in energy than their enol counterpart by less than $20 \mathrm{kcal} \mathrm{mol}^{-1}$. Structural analysis of the $\alpha$ substituted imines and amines in terms of the functional group suggests that the $\mathrm{C}=\mathrm{NH}$ and $\mathrm{C}=\mathrm{C}-\mathrm{NH}$ groups correspond to keto-enol tautomerization of $\mathrm{C}=\mathrm{O}$ and $\mathrm{C}=\mathrm{C}$-OH groups [38].

Table 1 Crystal data and structure refinement for 2-[(2,4dimethoxyphenyl)amino]-1,3-thiazolidin-4-one (1 h)

\begin{tabular}{|c|c|}
\hline Formula & $\mathrm{C}_{11} \mathrm{H}_{12} \mathrm{~N}_{2} \mathrm{O}_{3} \mathrm{~S}$ \\
\hline Formula weight & 252.29 \\
\hline Temperature/K & $130(2)$ \\
\hline Wavelength/Å & 0.71073 \\
\hline Crystal system & Monoclinic \\
\hline Space group & $P 2_{1} / c$ \\
\hline$a / \AA ̊$ & $14.11229(15)$ \\
\hline$b / \AA$ & $10.02574(14)$ \\
\hline$c / \AA$ & $8.12131(12)$ \\
\hline$\alpha /^{\circ}$ & 90.00 \\
\hline$\beta /^{\circ}$ & $96.8434(11)$ \\
\hline$\gamma{ }^{\circ}$ & 90.00 \\
\hline $\mathrm{V} / \AA^{3}$ & $1140.87(3)$ \\
\hline$Z\left(Z^{\prime}\right)$ & $4(1)$ \\
\hline$D_{c} / \mathrm{g} \mathrm{cm}^{-3}$ & 1.469 \\
\hline$\mu / \mathrm{m} \mathrm{m}^{-1}$ & 0.281 \\
\hline$F(000)$ & 528 \\
\hline Crystal size/mm & $0.60 * 0.25 * 0.20$ \\
\hline$\theta$ range & $2.50-32.53^{\circ}$ \\
\hline $\operatorname{Max} / \min$. indices $h, k, l$ & $-20 \leq h \leq 21,-14 \leq k \leq 9,-12 \leq l \leq 9$ \\
\hline No. of data collected & 11162 \\
\hline Independent reflections & $3832\left(R_{\mathrm{int}}=0.0181\right)$ \\
\hline Completeness to $\theta_{\max }=25.00^{\circ} \%$ & 100 \\
\hline Restraints/parameters & $0 / 161$ \\
\hline Goodness-of-fit on $F^{2}$ & 1.030 \\
\hline Final $R$ indices $[I>2 \sigma(I)]$ & $\mathrm{R} 1=0.0298, \mathrm{wR} 2=0.0797$ \\
\hline $\mathrm{R}$ indices (all data) & $\mathrm{R} 1=0.0340, \mathrm{wR} 2=0.0826$ \\
\hline Largest diff. peak and hole/e $\AA^{3}$ & 0.476 and -0.268 \\
\hline
\end{tabular}


Table 2 The energy barrier between structures investigated in this paper $\Delta \mathrm{E}\left[\mathrm{kcal} \mathrm{mol}{ }^{-1}\right]$

\begin{tabular}{|c|c|c|c|c|c|c|c|c|}
\hline & $\mathrm{a}$ & b & $\mathrm{c}$ & $\mathrm{d}$ & $\mathrm{e}$ & $\mathrm{f}$ & $\mathrm{g}$ & $\mathrm{h}$ \\
\hline $\mathrm{a}$ & 0 & -1 & -12 & 20 & 12 & -5 & 10 & 22 \\
\hline b & & 0 & -11 & 21 & 13 & -5 & 11 & 23 \\
\hline $\mathrm{c}$ & & & 0 & 32 & 24 & 6 & 22 & 34 \\
\hline d & & & & 0 & -8 & -26 & -10 & 2 \\
\hline $\mathrm{e}$ & & & & & 0 & -18 & -2 & 10 \\
\hline $\mathrm{f}$ & & & & & & 0 & 15 & 28 \\
\hline $\mathrm{g}$ & & & & & & & 0 & 13 \\
\hline $\mathrm{h}$ & & & & & & & & 0 \\
\hline
\end{tabular}

Since the keto tautomers are generally lower in energy than their enol counterpart, it is reasonable to predict that the amines, in general, will be more stable than the imines. This fact is reflected in the CSD database. Moreover our calculations show that the most stable conformation is amine form $\mathrm{h}$, which is in agreement with the crystallographic study. Tables 1 and 2

\section{Tautomers and biological activity}

Taking into account the molecular interactions, it would be more informative to discuss some biologically important facts. The heteroatomic systems with 4-, 5-, 6membered rings are common structures in many drugs. Most of them occur in two or more tautomeric structures. The prevalent form of tautomerism is prototropy which refers to the relocation of a proton. Various tautomers of the same compound could differ in biological activity, also it is important to identify potential for tautomerization in heteroatomic systems. A drug with possible amine to imine ( $\mathrm{NH}$ to $\mathrm{N}$ ) tautomerism is a change that decreases the aromaticity of the heteroatomic system. Exemplary drugs could reveal probable $\mathrm{NH}$ to $\mathrm{O}$ tautomerism, commonly existing as the amide tautomers. Therefore, the centers for the formation intermolecular hydrogen bonds are provided. Many antiviral agents along with drugs used in treatment of HIV infections exhibit the potential $\mathrm{NH}$ to $\mathrm{N}$ and $\mathrm{NH}$ to $\mathrm{O}$ tautomerism [39]. The structure activity relationship revealed that thiazolidine ring is essential for antibacterial and antiviral activity [40]. From this perspective, studies of the literature data revealed that the negative charges of the oxygen of $\mathrm{C}=\mathrm{O}$ group and positive charge of nitrogen in $\mathrm{NH}$ contribute positively in favor of an antibacterial activity. It was hypothesized that difference in charges between two heteroatoms of the same dipolar pharmacophore site $\left(\mathrm{X}^{\delta-}-\mathrm{Y}^{\delta+}\right)$ may facilitate the inhibition of bacteria, more than viruses growth. Additionally this is in good agreement with the mode of antibacterial action of the compounds bearing $\left(\mathrm{X}^{\delta-}-\mathrm{Y}^{\delta+}\right)$ pharmacophore site [41]. The antiviral activity is related to possible secondary electronic interaction with the positively charged side chains of the virus target(s). It was further found that the activity increases with increase in negative charge of one heteroatom of the common pharmacophore fragment of the potential tautomer. This means, that topologically related pairs of atoms need to be close to each other to promote biological activity. The heterocyclic ring in adjacent position of NH could generate two imino-amino tautomeric forms, and two distinct four-membered pharmacophore sites are conducive to the activity of both antibacterial $\left(\mathrm{O}^{\delta^{-}-} \mathrm{NH}^{\delta^{+}}\right)$and antiviral activity $\left(\mathrm{O}^{\delta^{-}-} \mathrm{N}^{\delta^{-}}\right)$. A common way of visualizing the distribution of charge in a molecule is to map the electrostatic potential in the form of a 3D plot (or a 2D contour plot) of the electrostatic potential distribution (MEP). Regions of the electron density surface that are more negative than others in an MEP are colored red. Regions in the MEP that are less negative (or positive) are blue. The color spectrum indicates the trend in charge from most negative (red) through green and yellow (neutral) to positive (blue). It provides a visual method to understand the relative polarity of a molecule and serves as a useful quantity to explain hydrogen bonding, reactivity, and structure-activity relationship of molecules including biomolecules and drugs. It is the potential energy of a proton at a particular location near a molecule. In Fig. 5 the distribution of charge for a typical tautomer obtained in crystal state, i.e., c, d, h are depicted. The color code of these maps is in the range between -0.0697 a.u.

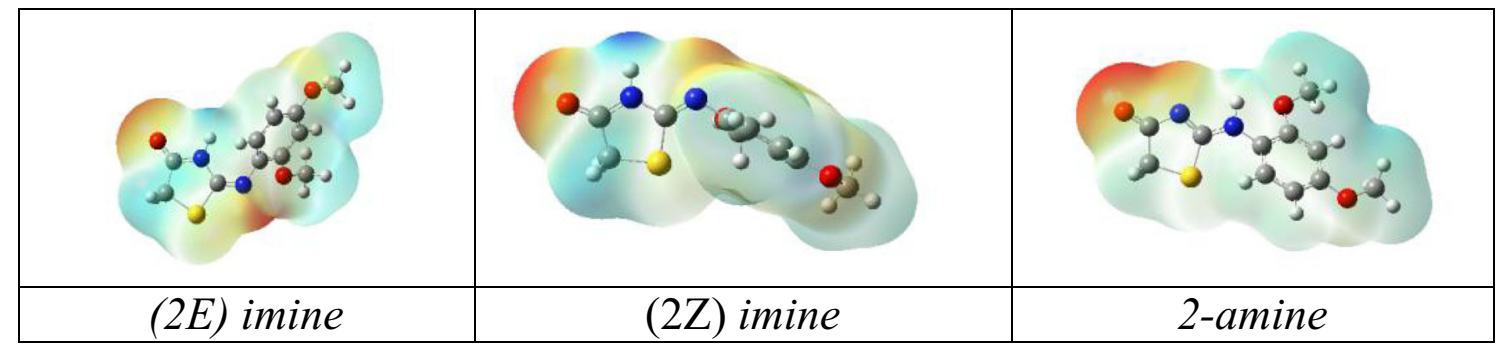

Fig. 5 The view of calculated contour electrostatic potential maps for typical tautomers presented in crystal state (c, d, h respectively) 
Fig. 6 From bottom to top: calculated infrared spectra of conformers $g$, $\mathrm{b}, \mathrm{d}, \mathrm{h}$. IR spectrum in the room temperature crystalline phase, as a $\mathrm{KBr}$ pellet

(deepest red) and 0.0697 a.u. The analysis of conformational differences due to heteroatom interactions in tautomers $\mathrm{a}-\mathrm{h}$ revealed a favorable $(\mathrm{C}=\mathrm{O}-\mathrm{NH}, \mathrm{C}-\mathrm{OH}-\mathrm{N})$ interaction in tautomer a-g, where tautomer h showed a repulsive $(\mathrm{C}=\mathrm{O}-\mathrm{N})$ interaction. The imine tautomer can exist as $\mathrm{E} / \mathrm{Z}$ stereoisomers as previously mentioned. As can be seen from the MEP, the compounds having E/Z configuration of imine has predicted higher probability of occurrence of antibacterial than its amine counterpart. In contrary, the amine spices have the higher chance to confirm antiviral activity in real pharmacological tests. The atomic charges for typical tautomers presented in crystal state (c, d, h respectively) are included in Table S8 in Supporting information.

\section{IR spectra}

The experimental geometry was in good agreement with the here calculated ab initio results. Consequently it seems reasonable to use these geometries to calculate force constancies and theoretical IR spectra. The title compound has 29 atoms and hence gives 81 (3 N-6) fundamental modes of vibration, all of them are IR active. Since the vibrational wavenumbers calculated by DFT methods are higher than their precise values, they were scaled down. In order to correct the effects of basis set limitations (neglecting part of electron correlation) and anharmonicity effects several methods of correction were implemented. In this work the wavenumbers are scaled applying the wavenumber linear scaling procedure (WLS) $\left[\gamma_{\mathrm{obs}} /\right.$ $v_{\text {cal }}=\left(1.0087-0.0000163 \times v_{\text {cal }}\right) \mathrm{cm}^{-1}$ ] by Yoshida et al. [42]. The computed harmonic frequencies are scaled down by a factor, 0.985 , obtained from linear fit of the calculated to experimental wavenumbers. The nature of stationary points on the potential energy surface was checked through the analysis of the corresponding Hessian matrix. The simulated spectrum reproduces very well the experimental spectrum, providing strong evidence for the presence of only keto forms in the solid state (Fig. 6). The comparison of experimental and calculated specific frequencies of important groups are collected in Table 3.

Taylor et al. reported the characteristic bands in the infrared spectra of several 2-substituted 4-thiazolidinones [4]. Typically in the infra-red spectrum in the solid state shows $\gamma \mathrm{C}=\mathrm{O}$ at $1718 \mathrm{~cm}^{-1}, v N H$ at $3015 \mathrm{~cm}^{-1}$ with $v \mathrm{C}=\mathrm{C}$ at $1532 \mathrm{~cm}^{-1}$ and $v \mathrm{C}=\mathrm{N}$ at $1638 \mathrm{~cm}^{-1}[43,17,12,11,16]$. The 4thiazolidinones with hydrogen attached to the nitrogen show absorption in the region $3100-3400 \mathrm{~cm}^{-1}$, characteristic of the $\mathrm{N}-\mathrm{H}$ stretching [44]. The latter statement was based on IR data obtained for different derivatives, showing a very strong
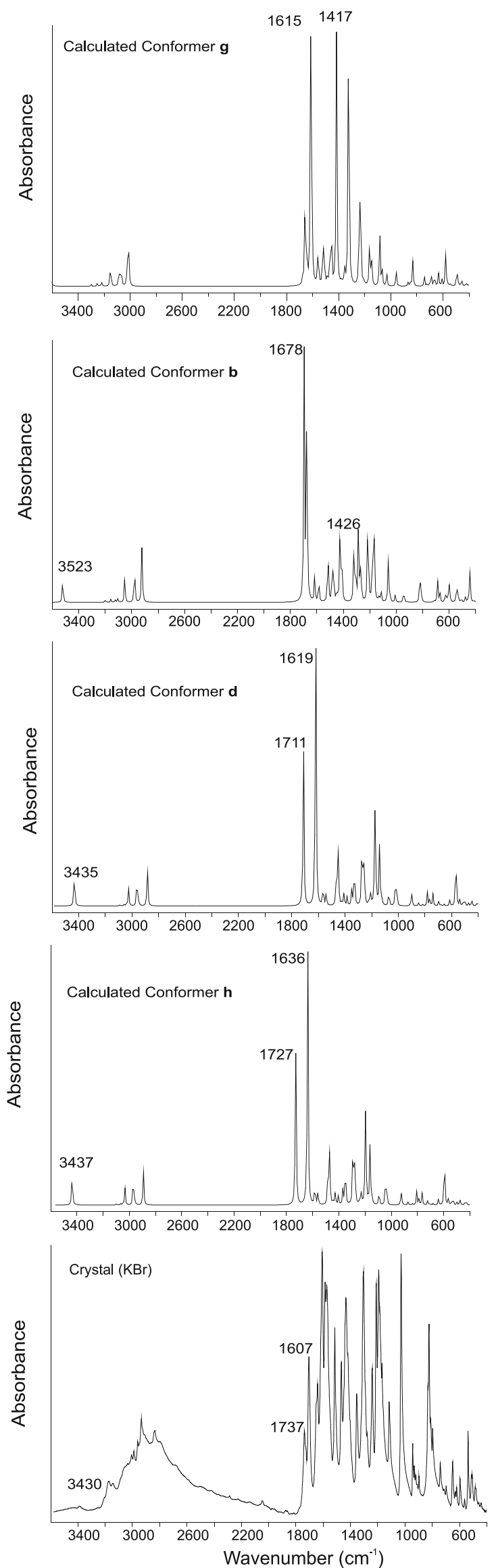
Table 3 Vibrational frequencies $\left(\mathrm{cm}^{-1}\right)$ of the selected groups obtained from solid state spectra and calculated using ab initio method

\begin{tabular}{llllll}
\hline Assignment & FTIR frequency & $\mathrm{h}$ & $\mathrm{d}$ & $\mathrm{b}$ & $\mathrm{g}$ \\
\hline $\mathrm{C}=\mathrm{O}$ & 1737 & 1727 & 1711 & - & - \\
$\mathrm{C}=\mathrm{N}$ & 1607 & 1636 & 1619 & 1678 & 1615 \\
$\mathrm{~N}-\mathrm{H}$ & 3430 & 3437 & 3435 & 3523 & - \\
$\mathrm{C}-\mathrm{OH}$ & - & - & - & 1426 & 1417 \\
\hline
\end{tabular}

X-ray crystallography

X-ray diffraction measurements were carried out on an Agilent Xcalibur A diffractometer [1]. The structure of 1 was solved by direct methods using the SHELXS-97 program [2]. Except for the amine $\mathrm{H}$ atom, which was refined freely the remaining $\mathrm{H}$ atoms were positioned geometrically and were refined within the riding model approximation, with $\mathrm{C}-\mathrm{H}=$ $0.96 \AA\left(\mathrm{CH}_{3}\right), 0.97 \AA\left(\mathrm{CH}_{2}\right), 0.93 \AA\left(\mathrm{C}_{a r} \mathrm{H}\right)$, and $U_{\text {iso }}(\mathrm{H})$ values were constrained to be 1.2 (1.5 for methyl group) times $U_{\text {eq }}$ of the appropriate carrier atom. The methyl $\mathrm{H}$ atoms were refined as a rigid group, which was allowed to rotate. The structure was refined by the full-matrix leastsquares method on $\mathrm{F}^{2} \mathrm{~s}$ using the SHELXL-97 program [2]. The crystal data, together with the details concerning the data collection and structure refinement are given in Table 1 and the atomic coordinates in Table 2. The crystallographic data in the CIF form are available as electronic supplementary information from the Cambridge Crystallographic Database Centre (CCDC 1003815). Molecular illustration was prepared using ORTEP-3 for Windows [3]. Software used to prepare material for publication was WINGX [3] and PLATON [4]

double bond $\mathrm{C}=\mathrm{N}$; absorption at $1640 \mathrm{~cm}^{-1}$, which is characteristic for an endocyclic $\mathrm{C}=\mathrm{N}$ [45]. Furthermore, the presence/absence of an amide II band between 1500 and $1575 \mathrm{~cm}^{-1}$ [46] confirm the assumption that the 2-amino form $\mathrm{h}$ is the predominant.

\section{Conclusions}

Thiazolidinones which belong to an important group of heterocyclic compounds have been widely explored for their applications in the field of medicine. During the last few decades this molecule has been a promising core structure for the search of new biologically active compounds due to their divers baiological potential. The aim of this study was to discuss the tautomerism of the $2-[(2,4-$ dimethoxyphenyl)amino]-1,3-thiazolidin-4-one. Based on the experimental X-ray analyses, FTIR spectroscopy and theoretical chemical calculations it was found that the minimum differences of energy was observed in imino (d) $\leftrightharpoons$ amino (h) pair, i.e., about $2 \mathrm{kcal} \mathrm{mol}^{-1}$. This proved that $2 \mathrm{Z}$ imine and amine counterpart is not experimentally accessible as isolate species. From a chemical point of view, another tautomerism such as keto $\leftrightharpoons$ enol is also possible. However, among the structures deposited in the CSD database none adopts the enol tautomeric form. The structure activity relationship revealed that thiazolidine ring is essential for antibacterial and antiviral activity [1, 3, 39]. Our MEP analysis showed that, the compounds having E/Z configuration of imine has predicted higher probability of occurrence of antibacterial than its amine counterpart. In contrary, the amine spices have the higher chance to confirm antiviral activity in real pharmacological tests.

Open Access This article is distributed under the terms of the Creative Commons Attribution License which permits any use, distribution, and reproduction in any medium, provided the original author(s) and the source are credited.

\section{References}

1. Jain AK, Vaidya A, Ravichandran V, Kashaw SK (2012) Recent developments and biological activities of thiazolidinone derivatives: a review. Bioorg Med Chem 20(11):3378-3395

2. Tripathi AC, Gupta SJ, Fatima GN, Sonar PK, Verma A, Saraf SK (2014) 4-Thiazolidinones: the advances continue. Eur J Med Chem 72:52-77

3. Devinyak O, Zimenkovsky B, Lesyk R (2013) Biologically active 4thiazolidinones: a review of QSAR studies and QSAR modeling of antitumor activity. Curr Top Med Chem 12(24):2763-2784

4. Verma A, Saraf SK (2008) 4-thiazolidinone - a biologically active scaffold. Eur J Med Chem 43(5):897-905

5. Prabhakar YS, Solomon VR, Gupta MK, Katti SB (2006) QSAR studies on thiazolidines: a biologically privileged scaffold. QSAR and molecular modeling studies in heterocyclic Drugs II. Springer, Berlin, pp 161-249

6. Singh SP, Parmar SS, Raman K, Stenberg VI (1981) Chemistry and biological activity of thiazolidinones. Chem Rev 81(2):175-203

7. Havrylyuk D, Mosula L, Zimenkovsky B, Vasylenko O, Gzella A, Lesyk R (2010) Synthesis and anticancer activity evaluation of 4thiazolidinones containing benzothiazole moiety. Eur J Med Chem 45(11):5012-5021

8. Havrylyuk D, Zimenkovsky B, Vasylenko O, Gzella A, Lesyk R (2012) Synthesis of new 4-thiazolidinone, pyrazoline and isatin based conjugates with promising antitumor activity. J Med Chem 55(20): $8630-8641$

9. Havrylyuk D, Zimenkovsky B, Vasylenko O, Lesyk R (2013) Synthesis and anticancer and antiviral activities of new 2pyrazoline-substituted 4-thiazolidinones. J Heterocycl Chem 50: E55-E62

10. Lesyk RB, Zimenkovsky BS, Kaminskyy DV, Kryshchyshyn AP, Havryluk DY, Atamanyuk DV, Subtel'na IY, Khyluk DV (2011) Thiazolidinone motif in anticancer drug discovery. Experience of DH LNMU medicinal chemistry scientific group. Biopolym Cell 27(2):107-117

11. Taylor PJ (1970) The infra-red spectroscopy of some 2-substituted thiazolid-4-ones, a new class of enamino-ketone. Elucidation of structure. Spectrochim Acta A-M 26(1):153-163

12. Taylor PJ (1976) The IR spectroscopy of some highly conjugated systems. Rationale of the investigation. Spectrochim Acta A-M 32(8):1471-1476

13. Enchev V, Chorbadjiev S, Jordanov B (2002) Comparative study of the structure of rhodanine, isorhodanine, thiazolidine-2, 4-dione, and thiorhodanine. Chem Heterocycl Compd 38(9):1110-1120 
14. Khovratovich NN, Chizhevskaya II (1967) The problem of the tautomerism of 2-iminothiazolidin-4-one and some of its derivatives. Chem Heterocycl Compd 3(2):513-515

15. Akerblom E (1967) 2-Aminothiazoline-4-one and 2-imnothiazolidine4-one derivatives. Part I The reaction of chloroacetic acid with Nmonoalkylthiourea. Acta Chem Scand 21:843-848

16. Akerblom E (1967) 2-Aminothiazoline-4-one and 2imnothiazolidine-4-one derivatives. Part II Tautomerism. Acta Chem Scand 21:1437-1442

17. Taylor PJ (1970) The infra-red spectroscopy of some 2-substituted thiazolid-4-ones, a new class of enamino-ketone: infra-red assignments and chemical implications. Spectrochim Acta A-M 26(1):165-194

18. Brown FC (1961) 4-Thiazolidinones. Chem Rev 61(5):463-521

19. Liebermann C (1881) Zur Constitution der Sulfhydantoine und Sulfurethane. Ann Chem 207:121-167

20. Liebermann C, Lange A (1879) Ueber die Formeln der Sulfhydantoine. Ber Dtsch Chem Ges 12:1588-1595

21. Ramsh SM, Smorygo NA, Ginak AI (1984) Structure of 2-amino-4thiazolinone. Chem Heterocycl Compd 20(8):865-869

22. Metwally MA, Farahat AA, Abdel-Wahab BF (2010) 2-Amino-4thiazolidinones: synthesis and reactions. J Sulfur Chem 31(4):315-349

23. Subtelna I, Atamanyuk D, Szymanska E, Kiec-Kononowicz K, Zimenkovsky B, Vasylenko O, Gzella A, Lesyk R (2010) Synthesis of 5-arylidene-2-amino-4-azolones and evaluation of their anticancer activity. Bioorg Med Chem 18(14):5090-5102

24. Sharpe SW, Johnson TJ, Sams RL, Chu PM, Rhoderick GC, Johnson PA (2004) Gas-phase databases for quantitative infrared spectroscopy. Appl Spectrosc 58(12):1452-1461

25. Parr RG, Weitao Y (1994) Density-functional theory of atoms and molecules, vol 16. Oxford University Press, USA

26. Becke AD (1993) Density-functional thermochemistry. III. The role of exact exchange. J Chem Phys 98:5648

27. Vosko SH, Wilk L, Nusair M (1980) Accurate spin-dependent electron liquid correlation energies for local spin density calculations: a critical analysis. Can J Phys 58(8):1200-1211

28. Lee C, Yang W, Parr RG (1988) Development of the Colle-Salvetti correlation-energy formula into a functional of the electron density. Phys Rev B 37:785

29. Ditchfield R, Hehre WJ, Pople JA (1971) Self-consistent molecularorbital methods. IX An extended Gaussian-type basis for molecularorbital studies of organic molecules. J Chem Phys 54:724-728

30. Frisch MJ, Pople JA, Binkley JS (1984) Self-consistent molecular orbital methods 25. Supplementary functions for Gaussian basis sets. J Chem Phys 80:3265-3269

31. Steel PJ, Guard JAM (1994) Heterocyclic tautomerism. VI. A redetermination and reassignment of the structure of 2-aminothiazol-4 (5H)-one (pseudothiohydantoin). Acta Cryst C 50(11):1721-1723
32. Lesyk R, Vladzimirska O, Holota S, Zaprutko L, Gzella A (2007) New 5-substituted thiazolo [3, 2- b] [1, 2, 4] triazol-6-ones: synthesis and anticancer evaluation. Eur J Med Chem 42(5):641-648

33. Ostapiuk YV, Obushak MD, Matiychuk VS, Naskrent M, Gzella AK (2012) A convenient method for the synthesis of 2-[(5-benzyl-1, 3thiazol-2-yl) imino]-1, 3-thiazolidin-4-one derivatives. Tetrahedron Lett 53(5):543-545

34. Kaminskyy D, Gzella AK, Lesyk R (2014) Cyclocondensation of thioamides and haloacetic acid derivatives provides inly 4thiazolidinones; isomeric 5-thiazolidinones were not observed. Synth Commun 44:231-236

35. Allen FH (2002) The Cambridge Structural Database: a quarter of a million crystal structures and rising. Acta Cryst B 58(3):380-388

36. Haynes WM, Lide DR, Bruno TJ (2012) CRC handbook of chemistry and physics 2012-2013. CRC, Boca Raton

37. Allen FH, Kennard O, Watson DG, Brammer L, Orpen AG, Taylor R (1987) Tables of bond lengths determined by X-ray and neutron diffraction. Part 1. Bond lengths in organic compounds. J Chem Soc Perkin Trans 2(12):S1-S19

38. Lin JF, Wu CC, Lien MH (1995) Ab initio study on the imineenamine tautomerism of the. alpha-substituted imines $(\mathrm{XH} 2 \mathrm{CCH}$ : $\mathrm{NH}, \mathrm{X}=\mathrm{H}, \mathrm{BH} 2, \mathrm{CH} 3, \mathrm{NH} 2, \mathrm{OH}, \mathrm{F}, \mathrm{Cl}, \mathrm{CN}, \mathrm{NO}$ ). J Phys Chem 99(46):16903-16908

39. Katritzky AR, Hall CD, El-Gendy BE-DM, Draghici B (2010) Tautomerism in drug discovery. J Comput-Aided Mol Des 24(6-7): 475-484

40. Bonde CG, Gaikwad NJ (2004) Synthesis and preliminary evaluation of some pyrazine containing thiazolines and thiazolidinones as antimicrobial agents. Bioorg Med Chem 12(9):2151-2161

41. Chohan ZH, Youssoufi MH, Jarrahpour A, Ben Hadda T (2010) Identification of antibacterial and antifungal pharmacophore sites for potent bacteria and fungi inhibition: indolenyl sulfonamide derivatives. Eur J Med Chem 45(3):1189-1199

42. Yoshida H, Takeda K, Okamura J, Ehara A, Matsurra H (2002) A new approach to vibrational analysis of large molecules by density functional theory: wavenumber-linear scaling method. J Phys Chem A 106(14):3580-3586

43. Anderluh M, Jukic M, Petric R (2009) Three-component one-pot synthetic route to 2-amino-5-alkylidene-thiazol-4-ones. Tetrahedron 65(1):344-350

44. Abhinit M, Ghodke M, Pratima NA (2009) Exploring potential of 4thiazolidinone: a brief review. Int J Pharm Pharm Sci 1:57-64

45. Socrates G, Socrates G (2001) Infrared and Raman characteristic group frequencies: tables and charts. John Wiley \& Sons Inc, Chichester

46. Coates J (2000) Interpretation of infrared spectra, a practical approach. Encyclopedia of analytical chemistry. Wiley, New York 